\title{
A Simple Three-Dimensional Failure Criterion for Jointed Rock Masses under True Triaxial Compression
}

\author{
Yaohui Gao $\mathbb{D}^{1}{ }^{1}$ Chunsheng Zhang, ${ }^{1}$ Zhaofeng Wang $\mathbb{D}^{2,3}$ and Jun Chen ${ }^{1}$ \\ ${ }^{1}$ PowerChina Huadong Engineering Corporation Limited, Hangzhou 310014, Zhejiang, China \\ ${ }^{2}$ State Key Laboratory of Geomechanics and Geotechnical Engineering, \\ Institute of Rock and Soil Mechanics Chinese Academy of Sciences, Wuhan 430071, China \\ ${ }^{3}$ University of Chinese Academy of Sciences, Beijing 100049, China \\ Correspondence should be addressed to Zhaofeng Wang; zfwang@whrsm.ac.cn
}

Received 1 April 2021; Accepted 17 May 2021; Published 27 May 2021

Academic Editor: Dongsheng Huang

Copyright (C) 2021 Yaohui Gao et al. This is an open access article distributed under the Creative Commons Attribution License, which permits unrestricted use, distribution, and reproduction in any medium, provided the original work is properly cited.

\begin{abstract}
The joint configuration and the intermediate principal stress have a significant influence on the strength of rock masses in underground engineering. A simple three-dimensional failure criterion is developed in this study to predict the true triaxial strength of jointed rock masses. The proposed failure criterion in the deviatoric and meridian planes adopts the elliptic and hyperbolic forms to approximate the Willam-Warnke and Mohr-Coulomb failure criterion, respectively. The four parameters in the proposed failure criterion have close relationships with the cohesion and the internal friction angle and can be linked with the joint inclination angle using a cosine function. Two suits of true triaxial strength data are collected to validate the correctness of the proposed failure criterion. Compared with other failure criteria, the proposed failure criterion is more reasonable and acceptable to describe the strength of jointed rock masses.
\end{abstract}

\section{Introduction}

Rock mass strength is an extremely important parameter in predicting the stability of geoengineering such as rock slopes, dam foundation, and deeply buried tunnels [1]. Due to the existing joints, rock mass strength is anisotropic [2-8]. In addition, true triaxial stress state $\left(\sigma_{1}>\sigma_{2}>\sigma_{3}\right)$ is more universal with the increasing depth of engineering. The influence of $\sigma_{2}$ on the compressive strength of jointed rock masses has been investigated extensively in the experimental tests [9-14]. Therefore, establishing a strength criterion considering both the joint and $\sigma_{2}$ dependency is essential for better designing the layout and construction of underground engineering.

A large number of research papers are concentrated on rock strength. Among others, the Mohr-Coulomb failure criterion [15] and the Hoek-Brown failure criterion [16] are most widely used because of their simplicities. However, these two failure criteria ignore the $\sigma_{2}$ effect. Based on the true triaxial strength data, the authors in [17-21] have proposed the three-dimensional failure criteria which can describe the variation in the rock strength with increasing $\sigma_{2}$ very well. There are also some popular true triaxial failure criteria [22-24]. However, these failure criteria are applicable for intact rock and do not consider the joint effect.

To develop a failure criterion considering the joint effect under true triaxial compression, Tiwari and Rao [14] introduced the joint effect into the generalized von Mises theory [20]. In addition, enormous research studies [25-27] have extended the Hoek-Brown failure criterion into the three-dimensional form to predict rock mass strength. Moreover, Singh and Singh and Zhang et al. [28, 29] established a modified Mohr-Coulomb criterion for the polyaxial strength of rock masses, and Rafiai [30] proposed an empirical criterion for rock mass strength under multiaxial state on the basis of a comprehensive experimental database. Based on the research in $[7,10,30]$, the modified nonlinear criteria are presented to determine the strength of rock masses. 
Most of the abovementioned failure criteria can only consider the effect of the joint or $\sigma_{2}$ on the prediction of rock mass strength. In addition, some aforementioned failure surfaces in three-dimensional principal stress space are not absolutely continuous, which could present difficulties in numerical calculations. To overcome these problems, the true triaxial failure criterion proposed in this paper adopts the modified Willam-Warnke yield criterion and hyperbolic function in the deviatoric and meridian planes, respectively. Moreover, the adopted hyperbolic function takes the Mohr-Coulomb criterion as the asymptote in the meridian plane. To valid the correctness of the developed failure criterion, it is employed to fit two suits of true triaxial strength data of rock masses.

\section{A Failure Criterion for Jointed Rock Masses}

Within this paper, tensile stress is considered positive and compressive stress is negative. A general form of a failure criterion suggested in [31] can be expressed in a quadratic function:

$$
F\left(\tau_{\text {oct }}, \sigma_{\text {oct }}, \theta_{\sigma}\right)=\alpha \sigma_{\text {oct }}^{2}+\beta \sigma_{\text {oct }}+\gamma+{\overline{\sigma_{+}}}^{2}=0,
$$

where $\overline{\sigma_{+}}=\tau_{\text {oct }} / g\left(\theta_{\sigma}\right) ; \theta_{\sigma}$ is the Lode angle $\left(\theta_{\sigma}=\right.$ $\left.1 / 3 \cos ^{-1}\left(3 \sqrt{3} J_{3} / 2 J_{2}^{3 / 2}\right)\right)$, where $J_{2} \quad\left(J_{2}=1 / 6\left[\left(\sigma_{1}-\sigma_{2}\right)^{2}\right.\right.$ $\left.\left.\left(\sigma_{2}-\sigma_{3}\right)^{2}+\left(\sigma_{3}-\sigma_{1}\right)^{2}\right]\right)$ and $J_{3}\left(J_{3}=\left(\sigma_{1}-\sigma_{\text {oct }}\right)\left(\sigma_{2}-\sigma_{\text {oct }}\right)\right.$ $\left.\left(\sigma_{3}-\sigma_{\text {oct }}\right)\right)$ are the second and third invariants of the deviatoric stress tensor, respectively; $\tau_{\text {oct }}$ and $\sigma_{\text {oct }}$ are the octahedral shear and normal stresses $\left(\tau_{\text {oct }}=1 / 3 \sqrt{\left(\sigma_{1}-\sigma_{2}\right)^{2}+\left(\sigma_{2}-\sigma_{3}\right)^{2}+\left(\sigma_{3}-\sigma_{1}\right)^{2}} \quad\right.$ and $\left.\sigma_{\text {oct }}=\left(\sigma_{1}+\sigma_{2}+\sigma_{3}\right) / 3\right)$; and $\alpha, \beta$, and $\gamma$ are material constants. First, the dependency of $\tau_{\text {oct }}$ on $\theta_{\sigma}$ in the deviatoric plane perpendicular to the hydrostatic axis is determined; namely, $g\left(\theta_{\sigma}\right)$ is obtained. Then, the influence of $\sigma_{\text {oct }}$ on $\overline{\sigma_{+}}$ can be investigated in the meridian plane.

\subsection{True Triaxial Failure Criterion in the Deviatoric Plane.} The failure curve in the deviatoric plane displays the following significant characteristics of rock failure: (i) continuous, smooth, and convex; (ii) a closed curve or vertex; and (iii) symmetric with respect to three principal stress axes. For this purpose, an elliptical form developed in [32] is adopted here to express the relationship between $g\left(\theta_{\sigma}\right)$ and $\theta_{\sigma}$ :

$$
g\left(\theta_{\sigma}\right)=\frac{R+(2 K-1) \sqrt{2 R \cos \theta_{\sigma}+5 K^{2}-4 K}}{2 R \cos \theta_{\sigma}+(1-2 K)^{2}},
$$

where $R=2\left(1-K^{2}\right) \cos \theta_{\sigma} ; K$ is the ratio $\left(K=\tau_{\text {oct }, a e} / \tau_{\text {oct }, a c}\right)$ between the strength $\left(\tau_{\text {oct,ae }}\right)$ for axisymmetric extension and the strength $\left(\tau_{\text {oct }, a c}\right)$ for axisymmetric compression; $0^{\circ} \leq \theta_{\sigma} \leq$ $60^{\circ}$ and $\theta_{\sigma}=0^{\circ}\left(g\left(\theta_{\sigma}\right)=K\right)$ for axisymmetric extension; and $\theta_{\sigma}=60^{\circ} g\left(\theta_{\sigma}\right)=1$ for axisymmetric compression.

It is notable that $g\left(\theta_{\sigma}\right)$ in (2) unconditionally satisfies the abovementioned properties of a failure criterion in the deviatoric plane for the range $0.5 \leq K \leq 1$. Therefore, taking $\theta_{\sigma}$ as the independent variable, $g\left(\theta_{\sigma}\right)$ is only a function of $K$.

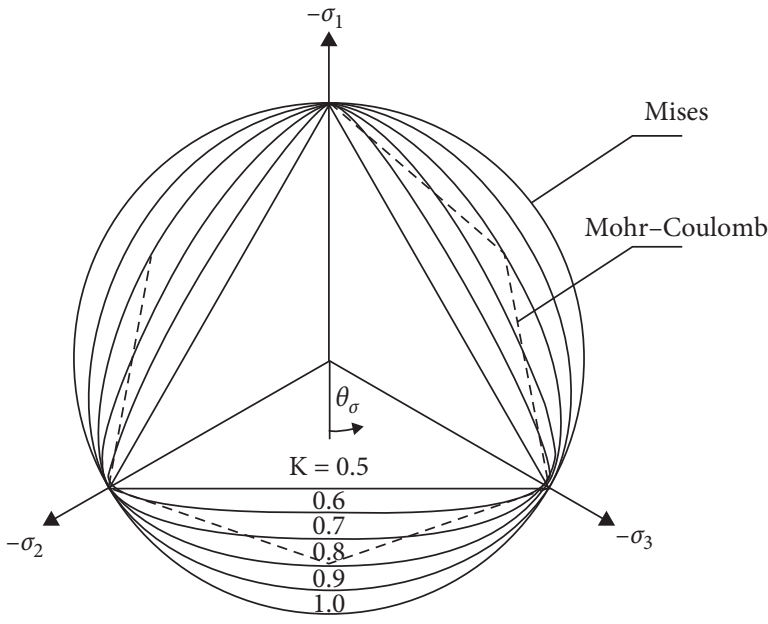

FIgURE 1: The Willam-Warnke failure criterion in the deviatoric plane with different $\mathrm{K}$ values.

Figure 1 shows that the shapes of the failure curves in the deviatoric plane changes with $K$. More specifically, as $K$ varies from 0.5 to 1 , failure surfaces gradually change from a triangle to a circle. It can be seen that the Willam-Warnke failure criterion is more appropriate than the Mohr-Coulomb failure criterion, and the Willam-Warnke criterion can change into the Mises criterion when $K=1$. Here, to present the joint effect on the failure function in the deviatoric plane, the parameter $K$ depends on both the joint inclination angle $\beta$ and $\sigma_{\text {oct }}$, namely, $K=K\left(\sigma_{\text {oct }}, \beta\right)$. If $K$ is constant at different $\sigma_{\text {oct }}, g\left(\theta_{\sigma}\right)$ is only a function of $\beta$. Thus, the joint inclination angle $\beta$ can describe the influence of the joint on the failure surfaces in the deviatoric plane.

2.2. True Triaxial Failure Criterion in the Meridian Plane. As pointed out by equation (1), once $g\left(\theta_{\sigma}\right)$ is determined using equation (2), a true triaxial failure criterion can be obtained if the relationship between $\overline{\sigma_{+}}$and $\sigma_{\text {oct }}$ is known. Here, a hyperbolic function (as shown in Figure 2) is adopted because of its simplicity and continuity to present the failure criterion in the meridian plane. Thus, equation (1) can be defined by

$$
F\left(\tau_{\text {oct }}, \sigma_{\text {oct }}, \theta_{\sigma}\right)=\left(\frac{\sigma_{\text {oct }}-d}{a}\right)^{2}-\left(\frac{\overline{\sigma_{+}}}{b}\right)^{2}-1=0
$$

where $a, b$, and $d$ are material constants. Figure 3 exhibits a typical failure surface of the proposed criterion in the principal stress space.

\subsection{Determination of the Parameters in the Failure Criterion.} Generally, equation (3) has four parameters: $K, a, b$, and $d$. As mentioned above, $K$ can be determined by the strength ratio under axisymmetric extension and compression at different $\beta$ and $\sigma_{\text {oct }}$ and be given by

$$
K=\frac{\tau_{o c t, a e}\left(\sigma_{o c t}, \beta\right)}{\tau_{o c t, a c}\left(\sigma_{o c t}, \beta\right)}
$$




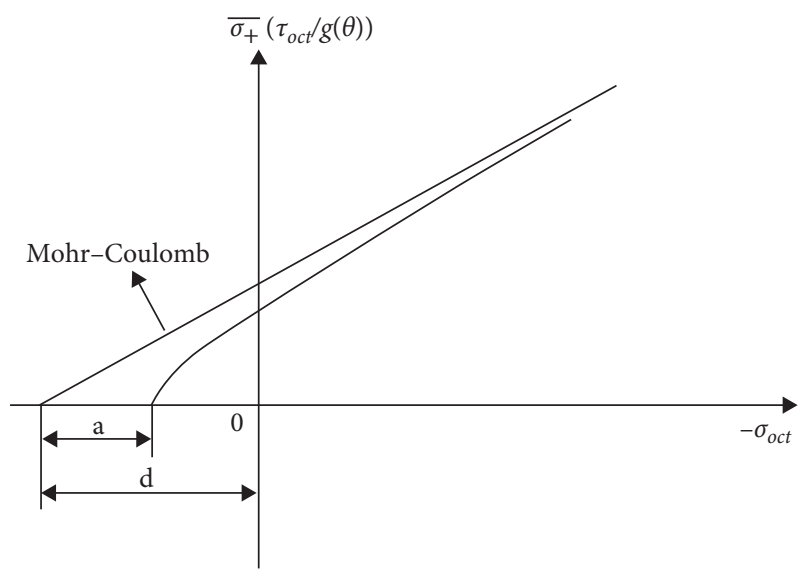

FIgURE 2: The hyperbolic function to approximate the Mohr-Coulomb failure criterion for axisymmetric compression in the meridian plane.

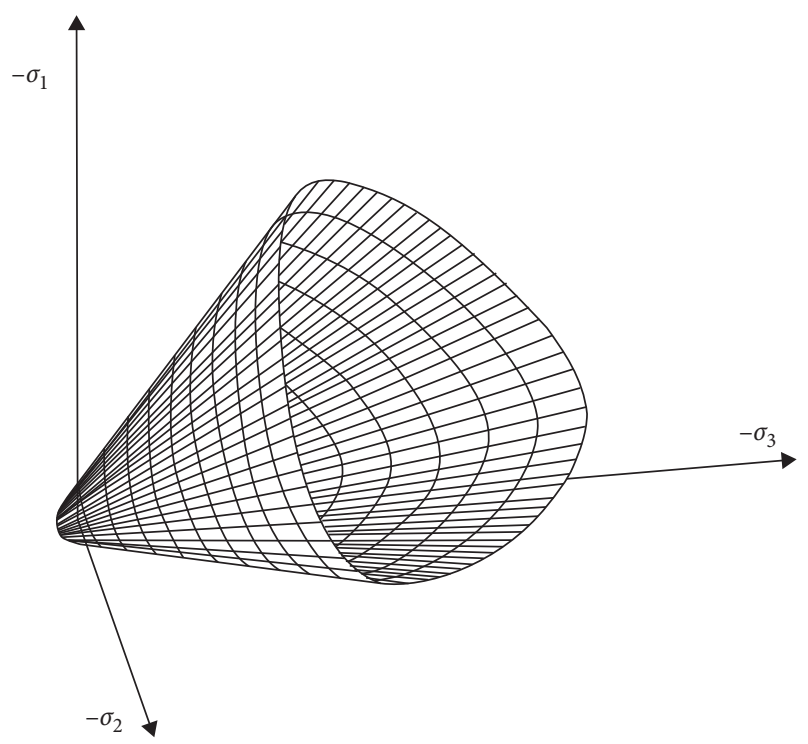

FIGURE 3: The typical failure surface in the principal stress space.

To determine the values of the other parameters, the hyperbolic function in equation (3) approximates the Mohr-Coulomb failure criterion for axisymmetric compression $\left(g\left(\theta_{\sigma}=60^{\circ}\right)=1\right)$ in the meridian plane (as shown in Figure 2). The Mohr-Coulomb failure criterion at $\theta_{\sigma}=$ $60^{\circ}$ can be expressed by

$$
F\left(\tau_{\mathrm{oct}}, \sigma_{\mathrm{oct}}, \theta_{\sigma}\right)=\overline{\sigma_{+}}+\frac{2 \sqrt{2} \sin \varphi}{3-\sin \varphi} \sigma_{\mathrm{oct}}-\frac{2 \sqrt{2} c \cos \varphi}{3-\sin \varphi}=0,
$$

where $c$ and $\varphi$ are the cohesion force and internal friction angle. Taking the Mohr-Coulomb line as the hyperbolic asymptote, the parameters $a, b$, and $d$ are then obtained as follows:

$$
\begin{aligned}
& \frac{b}{a}=\frac{2 \sqrt{2} \sin \varphi}{3-\sin \varphi} \\
& d=c \cot \varphi .
\end{aligned}
$$

The parameter $a$ can be fitted by a series of simple experimental tests under axisymmetric compression. As the parameter $a$ tends to be 0 , equation (3) is getting closer to the Mohr-Coulomb failure surfaces in the meridian plane. In addition, $g\left(\theta_{\sigma}\right)_{M C}$ in equation (5) is given by

$$
g\left(\theta_{\sigma}\right)_{M C}=\frac{3-\sin \varphi}{2 \sqrt{3} \cos \left(\left(\theta_{\sigma}-\pi\right) / 6\right)-2 \sin \varphi \sin \left(\left(\theta_{\sigma}-\pi\right) / 6\right)} .
$$

Thus, the strength ratio $K_{M C}$ under axisymmetric extension and compression can be calculated using the Mohr-Coulomb failure criterion.

$$
K_{M C}=g\left(\theta_{\sigma}=0^{\circ}\right)_{M C}=\frac{3-\sin \varphi}{3+\sin \varphi} .
$$

If equation (4) is simply substituted by equation (8), four unknown parameters $(K, a, b$, and $d)$ in equation (3) become three $(a, c$, and $\varphi)$ using equations (6) and (8). It is noted that the joint inclination angle $\beta$ affects the unknown parameters $(a(\beta), c(\beta)$, and $\varphi(\beta))$.

\section{Validation of the Proposed Failure Criterion}

The validity of the proposed failure criterion in this study is discussed using two following examples. The prediction accuracy is also analyzed and compared with other strength criteria.

3.1. Example 1. The true triaxial strength data for the first example are derived from the experimental results of [9]. This test was conducted on jointed marble which contains a natural joint plane with a rectangular prismatic size $\left(50 \times 50 \times 100 \mathrm{~mm}^{3}\right)$. Table 1 lists the derived test data.

The proposed failure criterion is used to model these selected strength data, and the calculated results are also listed in Table 1. Figure 4 presents the comparisons of the predicted strength $\sigma_{1 \text { cal }}$ with the experimental data $\sigma_{1 \text { exp. }}$. The reference line $\left(\sigma_{1 \mathrm{cal}}=\sigma_{1 \exp }\right)$ is also demonstrated in Figure 4 to exhibit the calculation accuracy. All of the data points are concentrated around the reference line, which indicates that the predictions by the proposed failure criterion are generally consistent with the experimental data.

The linear Mogi-Coulomb failure criterion [17] was adopted in [9] to fit the test data and is defined by

$$
\begin{aligned}
\tau_{\mathrm{oct}} & =\frac{2 \sqrt{2}}{3} c \cos \varphi+\frac{2 \sqrt{2}}{3} \sin \varphi \sigma_{m, 2}, \\
\sigma_{m, 2} & =\frac{\sigma_{1}+\sigma_{3}}{2}
\end{aligned}
$$

where $\sigma_{m, 2}$ is the effective mean stress. Here, the fitting results by these two failure criteria are compared in Figure 5, and the relationship between $\sigma_{1 \text { cal }}$ and $\sigma_{1 \exp }$ can be expressed by

$$
\begin{aligned}
& \sigma_{1 \mathrm{cal}}=1.0049 \sigma_{1 \exp }(R 2=0.9042) \\
& \sigma_{1 \mathrm{cal}}=1.0059 \sigma_{1 \exp }(R 2=0.9189)
\end{aligned}
$$


TABLE 1: True triaxial compression strength of experimental and predicted results of jointed marble (data from [9]; here, compressive stress is considered positive).

\begin{tabular}{|c|c|c|c|c|c|c|c|c|c|c|c|c|c|}
\hline \multirow[t]{2}{*}{$\sigma_{3}(\mathrm{MPa})$} & \multirow[t]{2}{*}{$\sigma_{2}(\mathrm{MPa})$} & \multicolumn{6}{|c|}{$\sigma_{1 \exp }(\mathrm{MPa})$, test data at joint inclination angle $\beta\left({ }^{\circ}\right)$} & \multicolumn{6}{|c|}{$\begin{array}{c}\sigma_{1 \text { cal }}(\mathrm{MPa}), \text { calculated data at joint inclination angle } \beta \\
\left({ }^{\circ}\right)\end{array}$} \\
\hline & & 0 & 20 & 40 & 60 & 80 & 90 & 0 & 20 & 40 & 60 & 80 & 90 \\
\hline 0 & 0 & 158.59 & 100.79 & 73.76 & 77.57 & 112.21 & 141.07 & 146.23 & 110.16 & 81.81 & 84.31 & 118.00 & 144.63 \\
\hline 10 & 60 & 279.94 & 296.43 & 272.40 & 240.12 & 242.96 & 258.62 & 276.72 & 254.21 & 220.28 & 202.30 & 224.88 & 240.92 \\
\hline 30 & 60 & 332.25 & 361.55 & 330.96 & 305.12 & 338.63 & 357.16 & 354.39 & 339.66 & 319.75 & 307.68 & 300.75 & 304.06 \\
\hline 30 & 90 & 409.76 & 387.18 & 363.12 & 337.69 & 311.01 & 297.24 & 395.24 & 384.82 & 363.43 & 337.62 & 330.11 & 331.26 \\
\hline 30 & 120 & 377.51 & 366.23 & 350.79 & 333.50 & 316.97 & 309.78 & 427.12 & 421.00 & 397.62 & 357.13 & 350.11 & 349.71 \\
\hline K & - & - & - & - & - & - & 0.7196 & 0.7221 & 0.7011 & 0.6651 & 0.7084 & 0.7272 & \\
\hline$a$ & - & - & - & - & - & - & 22.64 & 23.38 & 5.58 & 12.21 & 23.07 & 25.38 & \\
\hline$b$ & _ & _ & _ & - & - & - & 17.98 & 19.34 & 4.84 & 10.37 & 17.15 & 17.24 & \\
\hline$d$ & - & 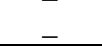 & - & - & - & - & 40.96 & 30.27 & 17.54 & 20.26 & 38.97 & 55.32 & \\
\hline
\end{tabular}

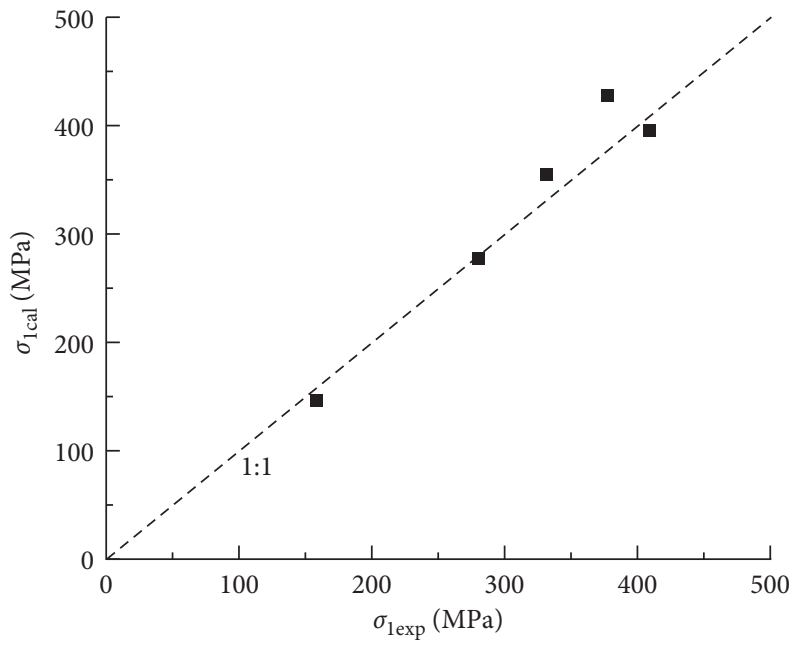

$\beta=0^{\circ}$

(a)

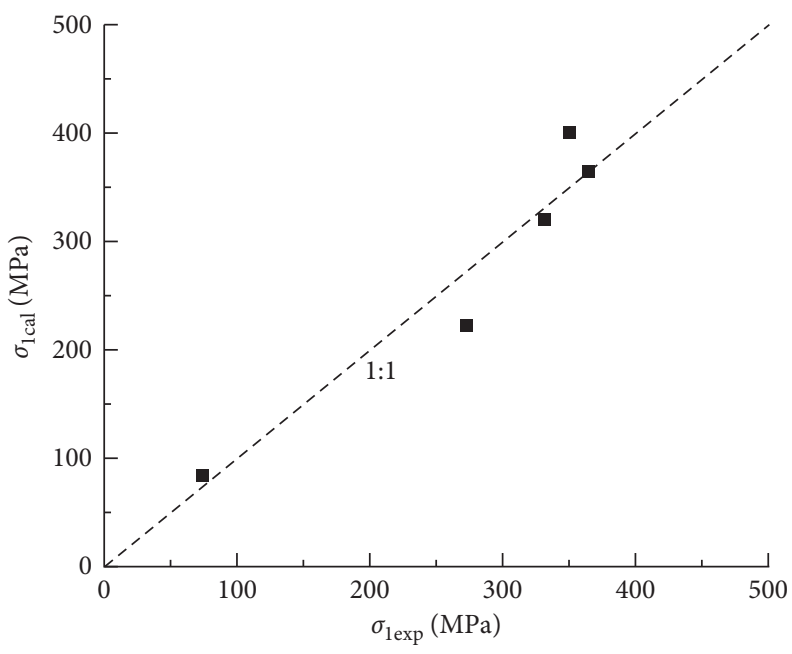

$\beta=40^{\circ}$

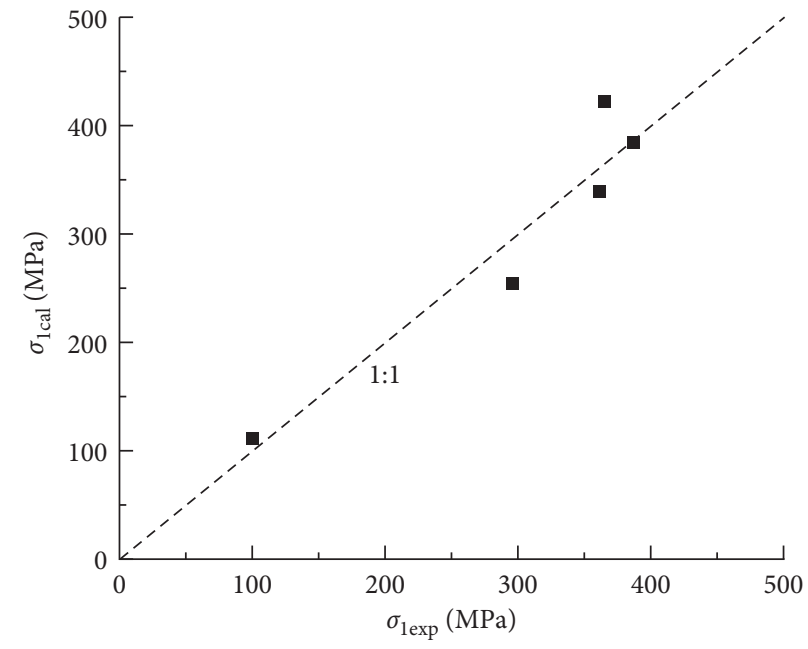

$\beta=20^{\circ}$

(b)

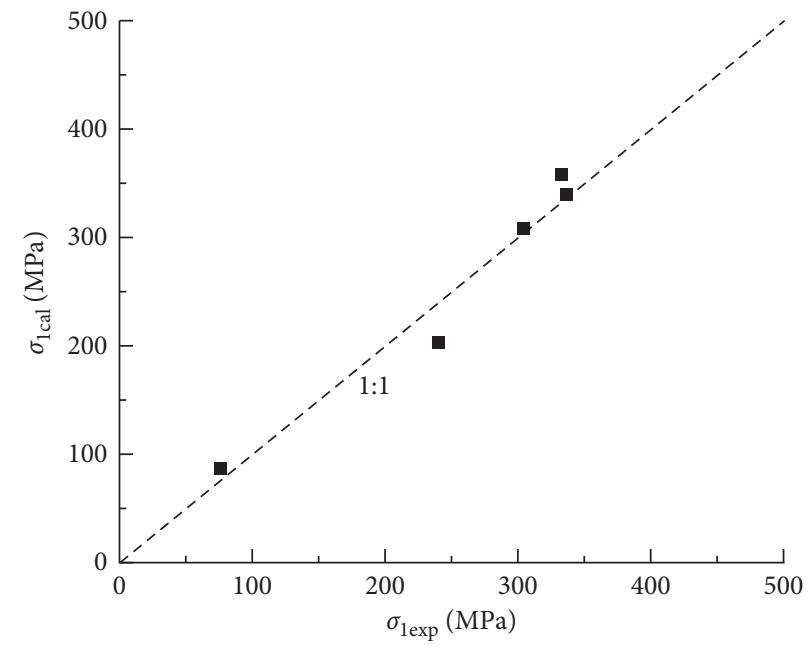

$\beta=60^{\circ}$

(c)

(d)

Figure 4: Continued. 


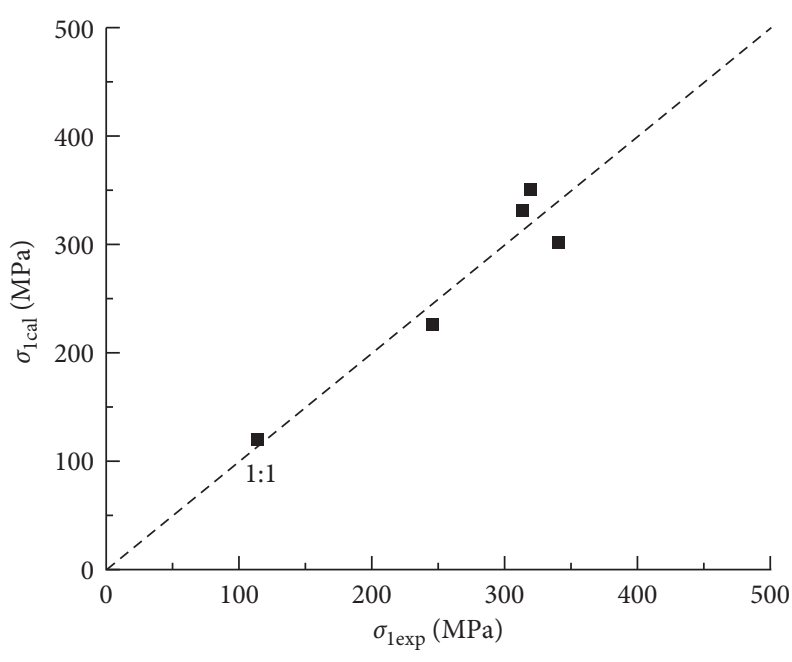

$\beta=80^{\circ}$

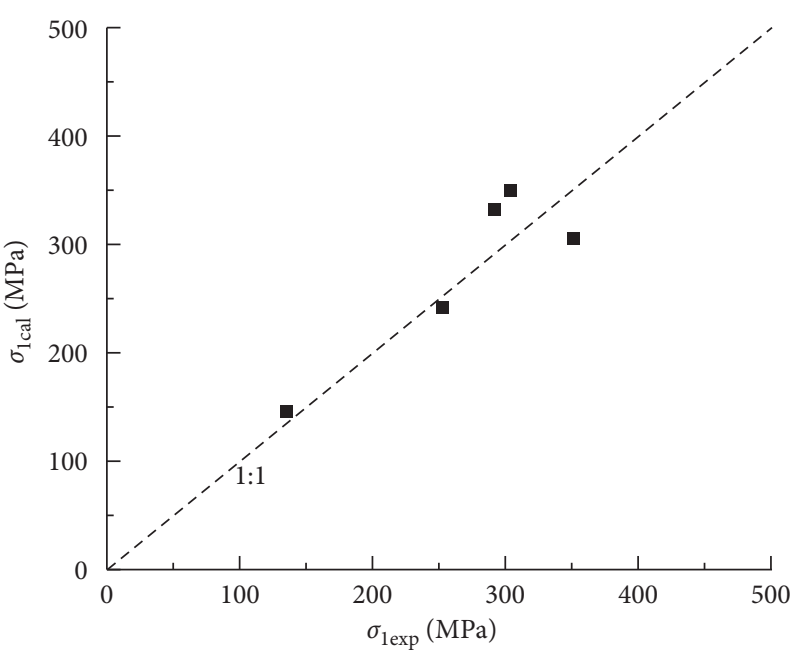

$\beta=90^{\circ}$

(e)

(f)

FIGURE 4: The comparison results of the calculated and experimental strength of jointed marble for different joint inclination angles: (a-f) $\beta=0^{\circ}, 20^{\circ}, 40^{\circ}, 60^{\circ}, 80^{\circ}$, and $90^{\circ}$.

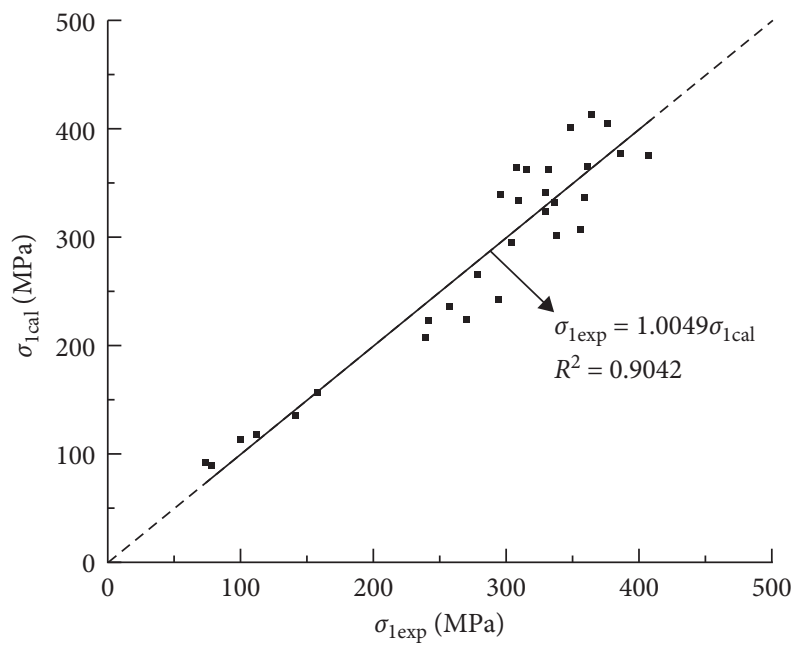

All data

Fitting line

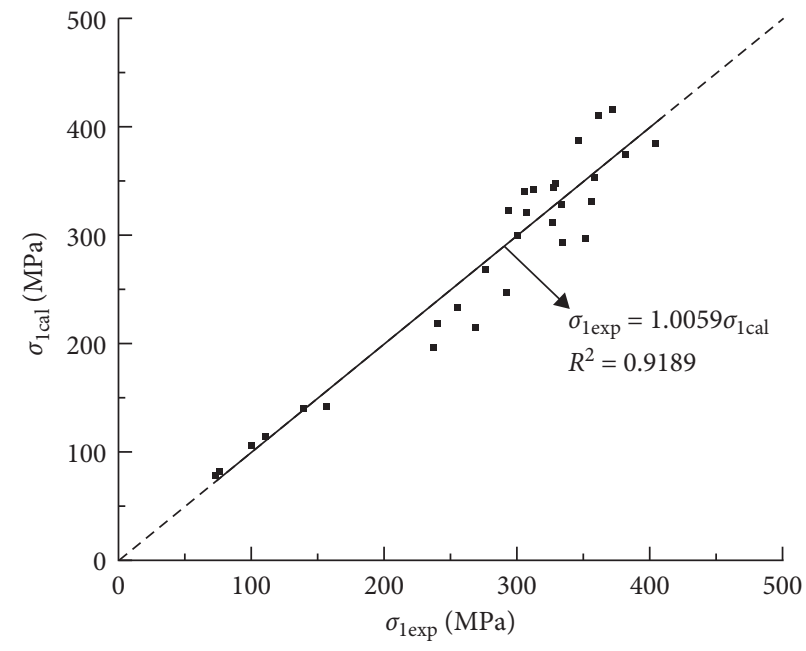

All data

Fitting line

(a)

(b)

Figure 5: The fitting results of all the experimental strength of jointed marble: (a) the linear Mogi-Coulomb failure criterion and (b) the proposed failure criterion.

where equation (10) refers to the fitting results by the linear Mogi-Coulomb and proposed failure criteria, respectively. Table 2 also shows the percentage error in predicting strength data of jointed marble. Obviously, the proposed failure criterion has higher accuracy than the Mogi-Coulomb criterion. Therefore, the proposed failure criterion is reasonable and applicable to predict the true triaxial strength of jointed rock masses.

3.2. Example 2. The strength data for example 2 are collected from the test results of [14]. This series of true triaxial tests 
TABLE 2: Percentage error in predicting strength data of jointed marble.

\begin{tabular}{|c|c|c|c|c|c|c|c|}
\hline \multirow{2}{*}{$\sigma_{3}(\mathrm{MPa})$} & \multirow{2}{*}{$\sigma_{2}(\mathrm{MPa})$} & \multicolumn{6}{|c|}{ Percentage error in predicting strength data at joint inclination angle $\beta\left(^{\circ}\right)$} \\
\hline & & 0 & 20 & 40 & 60 & 80 & 90 \\
\hline 0 & 0 & 7.79 & 9.30 & 10.91 & 8.69 & 5.16 & 2.52 \\
\hline 10 & 60 & 1.15 & 14.24 & 19.13 & 15.75 & 7.44 & 6.84 \\
\hline 30 & 60 & 6.66 & 6.05 & 3.39 & 0.84 & 11.19 & 14.87 \\
\hline 30 & 90 & 3.54 & 0.61 & 0.08 & 0.02 & 6.14 & 11.45 \\
\hline 30 & 120 & 13.14 & 14.95 & 13.35 & 7.09 & 10.46 & 12.89 \\
\hline \multirow{2}{*}{\multicolumn{2}{|c|}{$\begin{array}{l}\text { Average of this paper } \\
\text { Average of the Mogi-Coulomb } \\
\text { criterion [17] }\end{array}$}} & 6.46 & 9.03 & 9.37 & 6.48 & 8.08 & 9.71 \\
\hline & & 4.88 & 10.43 & 11.80 & 8.52 & 9.17 & 11.57 \\
\hline
\end{tabular}

TABLE 3: True triaxial compression strength of experimental and predicted results of rock mass models (data from [14]; here, compressive stress is considered positive).

\begin{tabular}{|c|c|c|c|c|c|c|c|c|c|c|c|c|c|}
\hline \multirow[t]{2}{*}{$\sigma_{3}(\mathrm{MPa})$} & \multirow[t]{2}{*}{$\sigma_{2}(\mathrm{MPa})$} & \multicolumn{6}{|c|}{$\begin{array}{c}\sigma_{1 \exp }(\mathrm{MPa}) \text {, test data at joint inclination } \\
\text { angle } \beta\left(^{\circ}\right)\end{array}$} & \multicolumn{6}{|c|}{ 1cal $(\mathrm{MPa})$, calculated data at joint inclination angle $\beta\left({ }^{\circ}\right)$} \\
\hline & & 0 & 20 & 40 & 60 & 80 & 90 & 0 & 20 & 40 & 60 & 80 & 90 \\
\hline 0.31 & 0.31 & 6.81 & 4.23 & 2.92 & 1.84 & 4.91 & 7.28 & 6.81 & 4.35 & 2.96 & 1.87 & 5.08 & 7.04 \\
\hline 0.31 & 0.59 & 7.78 & 5.01 & 5.32 & 2.85 & 6.76 & 8.68 & 7.42 & 5.05 & 3.85 & 2.27 & 5.71 & 7.66 \\
\hline 0.31 & 0.95 & 7.65 & 6.05 & 7.34 & 3.67 & 7.69 & 8.34 & 7.87 & 5.78 & 4.89 & 2.64 & 6.39 & 8.11 \\
\hline 0.31 & 1.22 & 9.32 & 7.41 & 7.96 & 4.24 & 8.27 & 7.33 & 8.09 & 6.26 & 5.62 & 2.86 & 6.84 & 8.35 \\
\hline 0.31 & 1.62 & 9.32 & 8.68 & 8.54 & 7.53 & 8.54 & 9.18 & 8.33 & 6.90 & 6.67 & 3.09 & 7.44 & 8.59 \\
\hline 0.78 & 0.78 & 9.76 & 7.23 & 6.26 & 3.54 & 7.73 & 9.54 & 9.76 & 6.99 & 6.18 & 3.47 & 7.39 & 10.05 \\
\hline 0.78 & 1.22 & 10.6 & 9.01 & 9.38 & 4.99 & 8.59 & 10.65 & 10.68 & 8.08 & 7.59 & 4.10 & 8.36 & 10.99 \\
\hline 0.78 & 2.24 & 11.45 & 10.6 & 11.91 & 7.66 & 10.86 & 11.97 & 11.67 & 10.03 & 10.52 & 5.08 & 10.13 & 12.00 \\
\hline 1.22 & 1.22 & 12.51 & 9.32 & 9.13 & 4.93 & 9.36 & 13.13 & 12.52 & 9.45 & 9.18 & 4.96 & 9.55 & 12.87 \\
\hline K & - & - & - & - & - & - & & 0.6109 & 0.7475 & 0.8433 & 0.8309 & 0.7666 & 0.6085 \\
\hline$a$ & - & - & - & - & - & - & & 0.001191 & 0.001393 & 0.001269 & 0.001199 & 0.001474 & 0.002107 \\
\hline$b$ & - & - & - & - & - & - & & 0.001073 & 0.001193 & 0.001185 & 0.000753 & 0.001179 & 0.001917 \\
\hline$d$ & - & - & - & - & - & - & & 0.9252 & 0.5677 & 0.1452 & 0.3420 & 0.9118 & 0.9330 \\
\hline
\end{tabular}

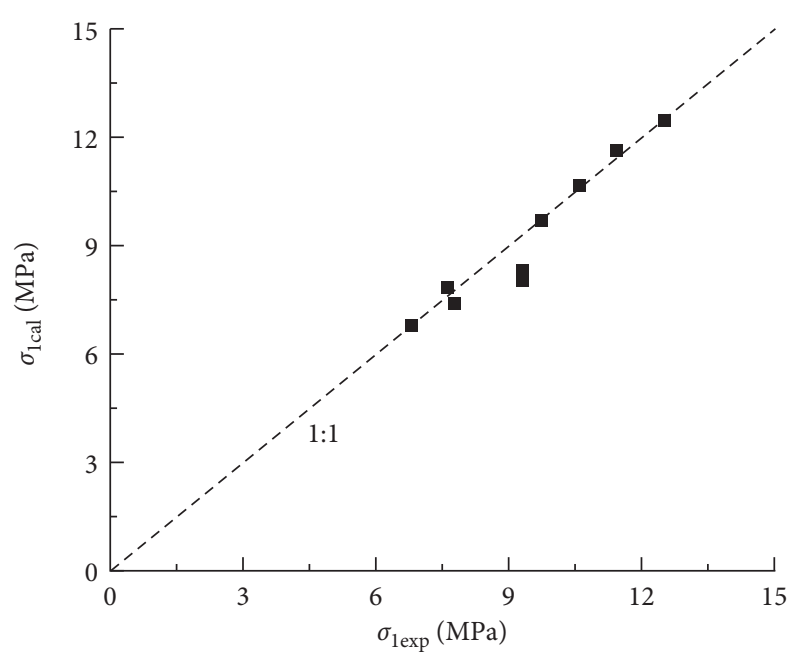

$\beta=0^{\circ}$

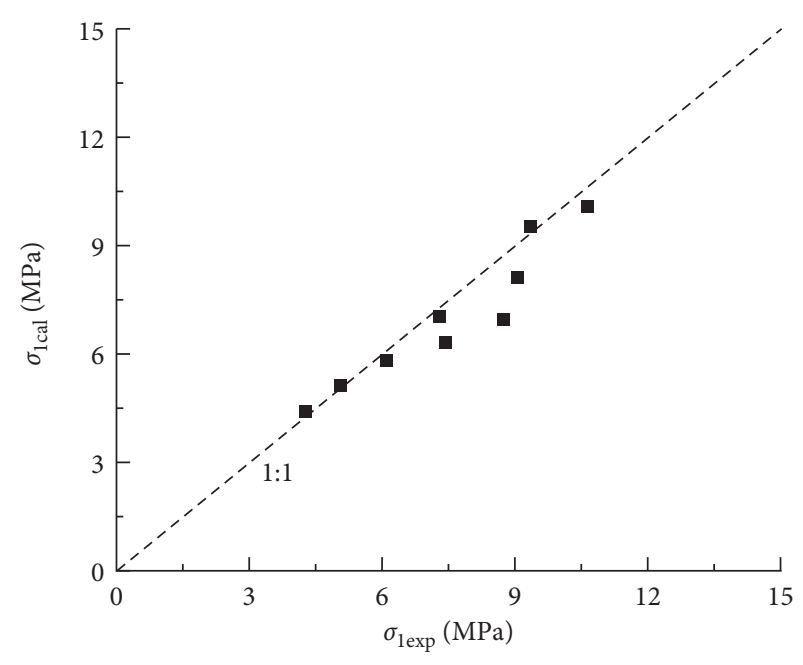

$\beta=20^{\circ}$

(a)

(b)

Figure 6: Continued. 


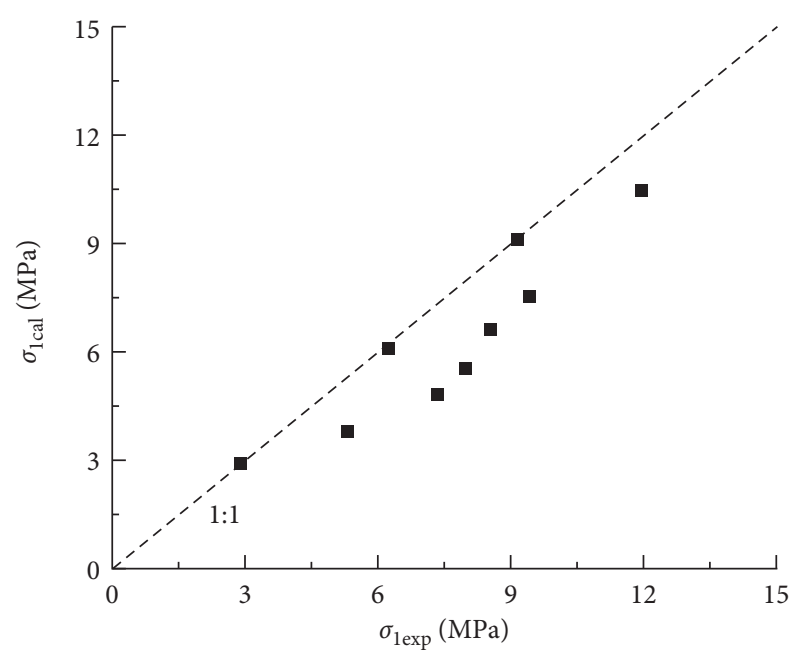

$\beta=40^{\circ}$

(c)

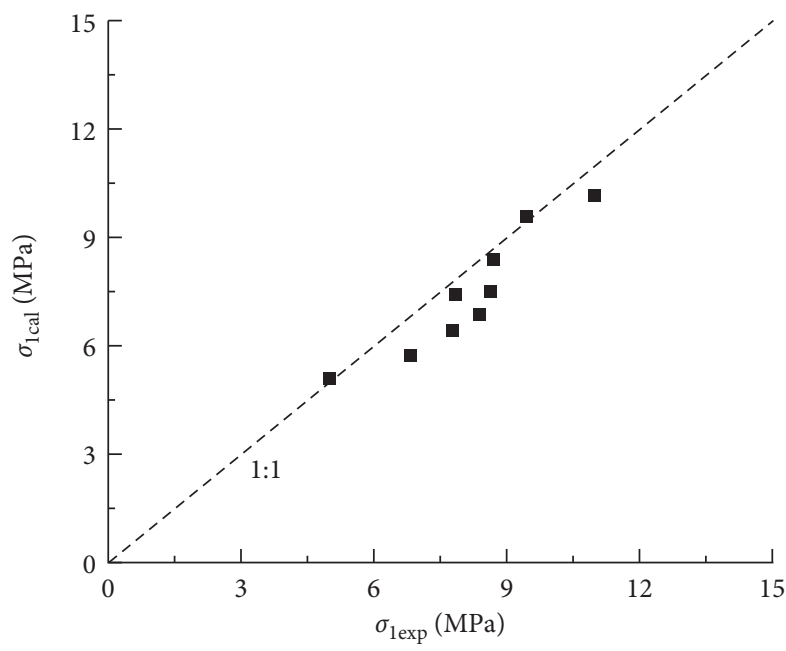

$\beta=80^{\circ}$

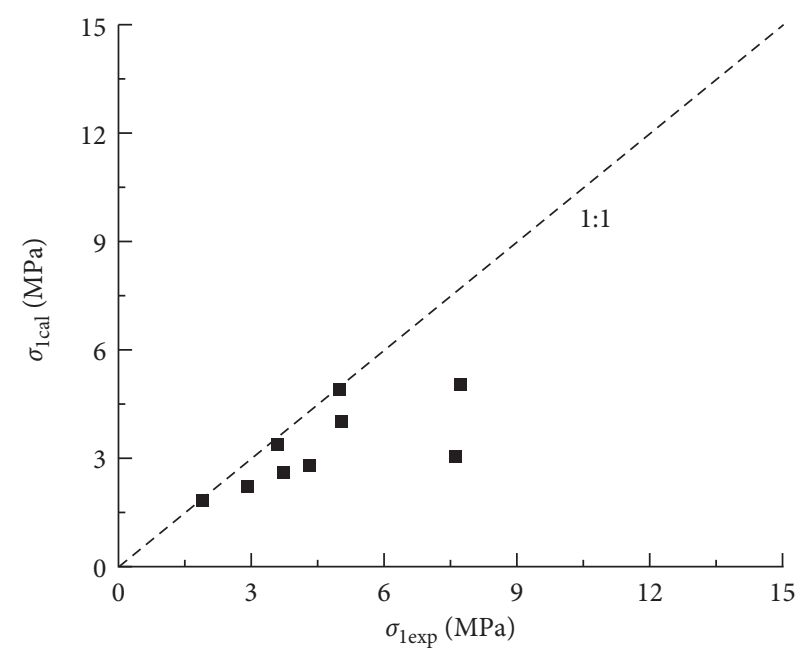

$\beta=60^{\circ}$

(d)

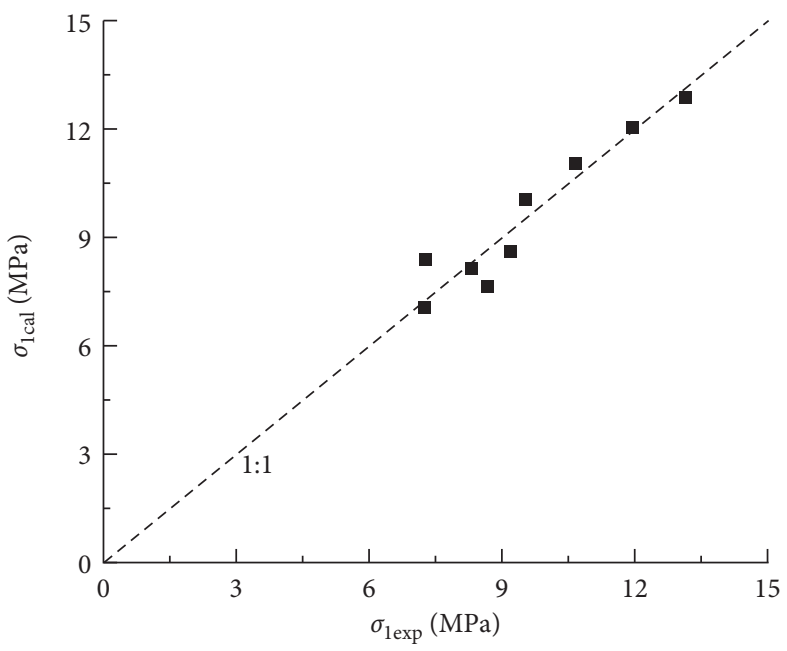

$\beta=90^{\circ}$

(e)

(f)

FIGURE 6: The comparison results of the calculated and experimental strength of jointed blocky mass for different joint inclination angles: (a-f) $\beta=0^{\circ}, 20^{\circ}, 40^{\circ}, 60^{\circ}, 80^{\circ}$, and $90^{\circ}$.

were carried out on rock mass models with different joint inclination angles, which is made using similar material and contains three joint sets. Table 3 summarizes the strength data of both experimental and calculated results.

Figure 6 shows the comparison results of the calculated and experimental strength of jointed blocky mass. The data points except the joint inclination $60^{\circ}$ are almost around the reference line. Thus, Figure 7 gives the fitting results of all the data and the data except the joint inclination $60^{\circ}$, and the relationship between $\sigma_{1 \mathrm{cal}}$ and $\sigma_{1 \exp }$ can be given by

$$
\begin{aligned}
& \sigma_{1 \mathrm{cal}}=0.9247 \sigma_{1 \exp }(\mathrm{R} 2=0.8738), \\
& \sigma_{1 \mathrm{cal}}=0.9400 \sigma_{1 \exp }(\mathrm{R} 2=0.9907),
\end{aligned}
$$

where equation (11) refers to the fitting results using all data and all data except the joint inclination $60^{\circ}$, respectively. In addition, two similar relationships suggested in $[10,28]$ are defined as follows:

$$
\begin{aligned}
& \sigma_{1 \text { cal }}=1.0150 \sigma_{1 \exp }(R 2=0.9383), \\
& \sigma_{1 \text { cal }}=1.0706 \sigma_{1 \exp }(R 2=0.8268) .
\end{aligned}
$$

Table 3 also exhibits the percentage error in predicting strength data of rock mass models using these three strength criteria. Generally, compared with the modified Mohr-Coulomb failure criterion [28] and the empirical strength criterion [10], the proposed failure criterion in this 


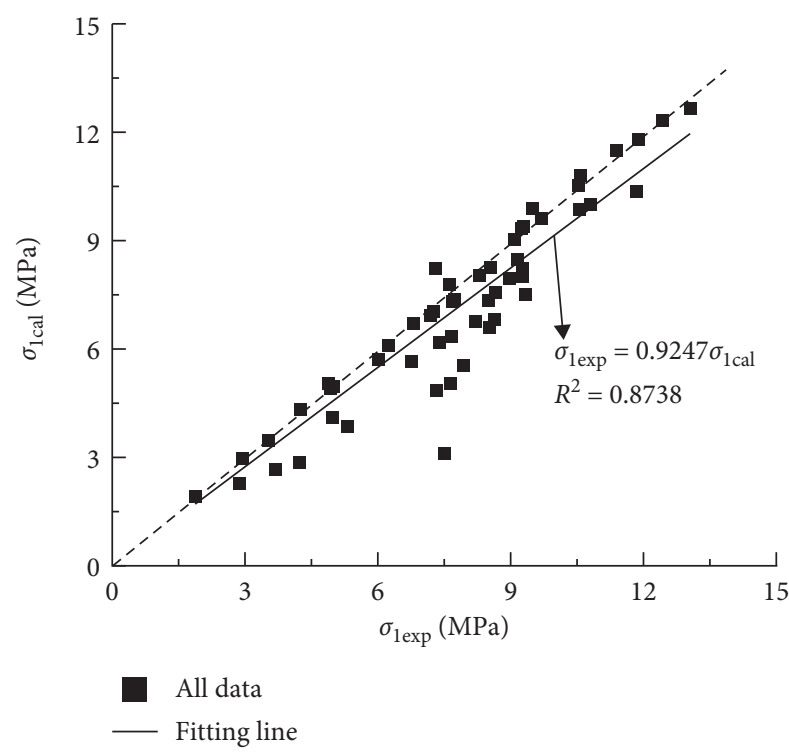

(a)

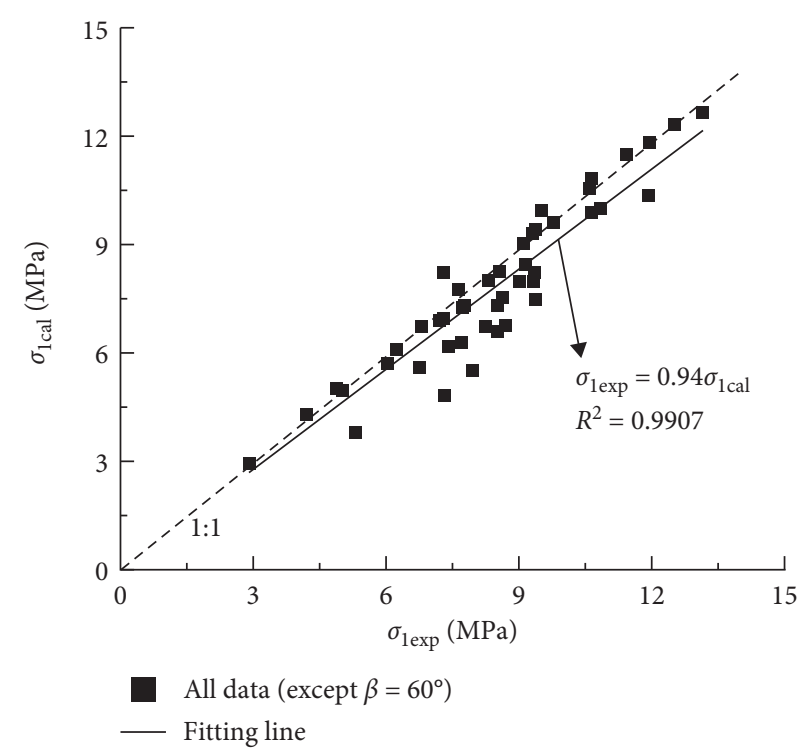

(b)

Figure 7: The fitting results of all the experimental strength of jointed blocky mass: (a) all the data and (b) all the data except $\beta=60^{\circ}$.

TABle 4: Percentage error in predicting strength data of rock mass models.

\begin{tabular}{|c|c|c|c|c|c|c|c|}
\hline \multirow[t]{2}{*}{$\sigma_{3}(\mathrm{MPa})$} & \multirow[t]{2}{*}{$\sigma_{2}(\mathrm{MPa})$} & \multicolumn{6}{|c|}{$\begin{array}{l}\text { Percentage error in predicting strength } \\
\text { data at joint inclination angle } \beta\left(^{\circ}\right)\end{array}$} \\
\hline & & 0 & 20 & 40 & 60 & 80 & 90 \\
\hline 0.31 & 0.31 & 0.06 & 2.90 & 1.52 & 1.77 & 3.52 & 3.35 \\
\hline 0.31 & & 4.62 & 0.77 & 27.55 & 20.33 & 15.56 & 11.79 \\
\hline 0.31 & 0.95 & 2.83 & 4.42 & 33.43 & 28.01 & 16.94 & 2.72 \\
\hline 0.31 & 1.22 & 13.15 & 15.50 & 29.41 & 32.63 & 17.32 & 13.89 \\
\hline 0.31 & 1.6 & 10.5 & 20.49 & 21.95 & 58. & 12. & 6.40 \\
\hline 0.78 & 0.78 & 0.01 & 3.35 & 1.35 & 2.01 & 4.41 & 5.35 \\
\hline 0.78 & 1.22 & 0.75 & 10.35 & 19.07 & 17.79 & 2.68 & 3.19 \\
\hline 0.78 & 2.24 & 1.88 & 5.42 & 11.68 & 33.63 & 6.73 & 0.25 \\
\hline 1.22 & 1.22 & 0.0 & 1.44 & & 0.68 & 2.00 & 1.97 \\
\hline \multicolumn{2}{|c|}{ Average of this paper } & 3.77 & 7.18 & 16.28 & 21.75 & 9.12 & 5.43 \\
\hline \multicolumn{2}{|c|}{ Average of [14] } & 8.70 & 11.30 & 15.30 & 49.60 & 13.30 & 11.80 \\
\hline \multicolumn{2}{|c|}{ Average of [10] } & 17.80 & 8.36 & 15.60 & 29.70 & 7.70 & 12.50 \\
\hline
\end{tabular}

study has higher correlation coefficient and smaller average percentage error, as shown in Table 4, which indicates that the proposed failure criterion is acceptable.

\section{Conclusions}

To investigate the influence of the joint orientation and $\sigma_{2}$ on the strength characteristics of jointed rock masses, a threedimensional failure criterion is developed and is validated by two examples of true triaxial test results. Some important conclusions can be drawn as follows:

(1) The proposed failure criterion in the deviatoric plane adopts the elliptic form based on the Willam-Warnke failure criterion. The joint effect is considered by only one parameter, strength ratio $K$.
(2) The proposed failure criterion in the meridian plane uses the hyperbolic function to approximate the Mohr-Coulomb failure criterion so that the parameters can be linked with the cohesion and the internal friction angle.

(3) The proposed failure criterion in the presented study can achieve small percentage error and high correlation coefficient to predict the true triaxial strength data in two examples.

\section{Data Availability}

The data used to support the findings of this study are available from the corresponding author upon request.

\section{Conflicts of Interest}

The authors declare that they have no conflicts of interest.

\section{Acknowledgments}

The authors sincerely acknowledge the financial support from the National Natural Science Foundation of China under grant nos. 51621006 and 51839003. The authors also express their gratitude for the support from the Key Laboratory of Ministry of Education on Safe Mining of Deep Metal Mines, Northeastern University.

\section{References}

[1] G. F. Liu, Q. Jiang, G. L. Feng, D. F. Chen, B. R. Chen, and Z. N. Zhao, "Microseismicity-based method for the dynamic estimation of the potential rockburst scale during tunnel excavation," Bulletin of Engineering Geology and the Environment, vol. 80, no. 4, pp. 3605-3628, 2021.

[2] L. R. Alejano, J. Arzúa, N. Bozorgzadeh, and J. P. Harrison, "Triaxial strength and deformability of intact and increasingly 
jointed granite samples," International Journal of Rock Mechanics and Mining Sciences, vol. 95, pp. 87-103, 2017.

[3] H. H. Einstein and R. C. Hirschfeld, "Model studies on mechanics of jointed rock," Journal of the Soil Mechanics and Foundations Division, vol. 99, no. 3, pp. 229-248, 1973.

[4] X. Hao, Y. Wei, K. Yang et al., "Anisotropy of crack initiation strength and damage strength of coal reservoirs," Petroleum Exploration and Development, vol. 48, no. 1, pp. 243-255, 2021.

[5] P. H. S. W. Kulatilake, J. Liang, and H. Gao, "Experimental and numerical simulations of jointed rock block strength under uniaxial loading," Journal of Engineering Mechanics, vol. 127, no. 12, pp. 1240-1247, 2001.

[6] M. H. B. Nasseri, K. S. Rao, and T. Ramamurthy, "Anisotropic strength and deformational behavior of himalayan schists," International Journal of Rock Mechanics and Mining Sciences, vol. 40, no. 1, pp. 3-23, 2003.

[7] O. Saeidi, V. Rasouli, R. G. Vaneghi, R. Gholami, and S. R. Torabi, "A modified failure criterion for transversely isotropic rocks," Geoscience Frontiers, vol. 5, no. 2, pp. 215-225, 2014.

[8] M. Singh, K. S. Rao, and T. Ramamurthy, "Strength and deformational behaviour of a jointed rock mass," Rock Mechanics and Rock Engineering, vol. 35, no. 1, pp. 45-64, 2002.

[9] Y. Gao, X.-T. Feng, Z. Wang, and X. Zhang, "Strength and failure characteristics of jointed marble under true triaxial compression," Bulletin of Engineering Geology and the Environment, vol. 905, no. 3, pp. 891-905, 2020.

[10] X. Liu, Q. Liu, Y. Kang, and Y. Pan, "Improved nonlinear strength criterion for jointed rock masses subject to complex stress states," International Journal of Geomechanics, vol. 18, no. 3, Article ID 04017164, 2018.

[11] P. Kapang, C. Walsri, T. Sriapai, and K. Fuenkajorn, "Shear strengths of sandstone fractures under true triaxial stresses," Journal of Structural Geology, vol. 48, pp. 57-71, 2013.

[12] M. A. Kwàsniewski and K. Mogi, "Effect of the intermediate principal stress on the failure of a foliated anisotropic rock," in Proceedings of the Third International Conference on Mechanics of Jointed and Faulted Rock, H. P. Rossmanith, Ed., Rotterdam, Netherlands, April 1990.

[13] G. Reik and M. Zacas, "Strength and deformation characteristics of jointed media in true triaxial compression," International Journal of Rock Mechanics and Mining Sciences \& Geomechanics Abstracts, vol. 15, no. 6, pp. 295-303, 1978.

[14] R. P. Tiwari and K. S. Rao, "Response of an anisotropic rock mass under polyaxial stress state," Journal of Materials in Civil Engineering, vol. 19, no. 5, pp. 393-403, 2007.

[15] J. F. Labuz and A. Zang, "Mohr-coulomb failure criterion," Rock Mechanics and Rock Engineering, vol. 45, no. 6, pp. 975-979, 2012.

[16] E. Hoek and E. T. Brown, "Empirical strength criterion for rock masses," Journal of Geotechnical Engineering, vol. 106, no. GT9, pp. 1013-1035, 1980.

[17] A. Al-Ajmi and R. W. Zimmerman, "Relation between the mogi and the coulomb failure criteria," International Journal of Rock Mechanics and Mining Sciences, vol. 42, no. 3, pp. 431-439, 2005.

[18] C. Chang and B. Haimson, "A failure criterion for rocks based on true triaxial testing," Rock Mechanics and Rock Engineering, vol. 45, no. 6, pp. 1007-1010, 2012.

[19] X. Ma, J. W. Rudnicki, and B. C. Haimson, "The application of a matsuoka-nakai-lade-duncan failure criterion to two porous sandstones," International Journal of Rock Mechanics and Mining Sciences, vol. 92, pp. 9-18, 2017.
[20] K. Mogi, "Fracture and flow of rocks under high triaxial compression," Journal of Geophysical Research, vol. 76, no. 5, pp. 1255-1269, 1971.

[21] X.-T. Feng, R. Kong, C. Yang et al., "A three-dimensional failure criterion for hard rocks under true triaxial compression," Rock Mechanics and Rock Engineering, vol. 53, no. 12, pp. 103-111, 2019.

[22] D. C. Drucker and W. Prager, "Soil mechanics and plastic analysis or limit design," Quarterly of Applied Mathematics, vol. 10, no. 2, pp. 157-165, 1952.

[23] P. V. Lade and J. M. Duncan, "Elastoplastic stress-strain theory for cohesionless soil," Journal of the Geotechnical Engineering Division, vol. 101, no. 10, pp. 1037-1053, 1975.

[24] G. A. Wiebols and N. G. W. Cook, "An energy criterion for the strength of rock in polyaxial compression," International Journal of Rock Mechanics and Mining Sciences \& Geomechanics Abstracts, vol. 5, no. 6, pp. 529-549, 1968.

[25] H. Jiang and J. Zhao, "A simple three-dimensional failure criterion for rocks based on the hoek-brown criterion," Rock Mechanics and Rock Engineering, vol. 48, no. 5, pp. 1807-1819, 2015.

[26] N. Melkoumian, S. D. Priest, and S. P. Hunt, "Further development of the three-dimensional Hoek-Brown yield criterion," Rock Mechanics and Rock Engineering, vol. 42, no. 6, pp. 835-847, 2009.

[27] L. Zhang and H. Zhu, "Three-dimensional hoek-brown strength criterion for rocks," Journal of Geotechnical and Geoenvironmental Engineering, vol. 133, no. 9, pp. 1128-1135, 2007.

[28] M. Singh and B. Singh, "Modified mohr-coulomb criterion for non-linear triaxial and polyaxial strength of jointed rocks," International Journal of Rock Mechanics and Mining Sciences, vol. 51, pp. 43-52, 2012.

[29] Q. Zhang, S. Wang, X. Ge, and H. Wang, "Modified MohrCoulomb strength criterion considering rock mass intrinsic material strength factorization," Mining Science and Technology (China), vol. 20, no. 5, pp. 701-706, 2010.

[30] H. Rafiai, "New empirical polyaxial criterion for rock strength," International Journal of Rock Mechanics and Mining Sciences, vol. 48, no. 6, pp. 922-931, 2011.

[31] O. C. Zienkiewicz and G. N. Pande, "Some useful forms of isotropic yield surfaces for soil and rock mechanics," in Finite Elements in Gemechanics, G. Godehus, Ed., Wiley, New York, NY, USA, 1977.

[32] K. J. Willam and E. P. Warnke, "Constitutive model for the triaxial behaviour of concrete," in Proceedings of the Presented at the Seminar on Concrete Structures Subjected to Triaxial Stresses, pp. 1-30, ISMES, Bergamo, Italy, June 1975. 